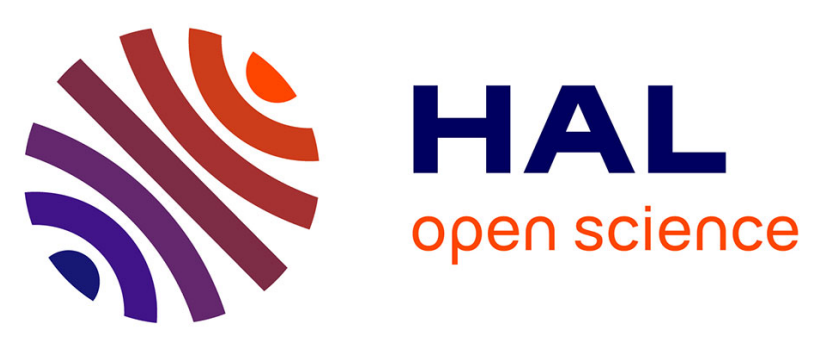

\title{
Bicarbonate Concentration Induces Production of Exopolysaccharides by Arthrospira platensis That Mediate Bioflocculation and Enhance Flotation Harvesting Efficiency
}

Jean-Baptiste Vergnes, Vincent Gernigon, Pascal Guiraud, Cécile Formosa-Dague

\section{To cite this version:}

Jean-Baptiste Vergnes, Vincent Gernigon, Pascal Guiraud, Cécile Formosa-Dague. Bicarbonate Concentration Induces Production of Exopolysaccharides by Arthrospira platensis That Mediate Bioflocculation and Enhance Flotation Harvesting Efficiency. ACS Sustainable Chemistry \& Engineering, 2019, 7 (16), pp.13796-13804. 10.1021/acssuschemeng.9b01591 . hal-02311400

\author{
HAL Id: hal-02311400 \\ https://hal.science/hal-02311400
}

Submitted on 15 Nov 2021

HAL is a multi-disciplinary open access archive for the deposit and dissemination of scientific research documents, whether they are published or not. The documents may come from teaching and research institutions in France or abroad, or from public or private research centers.
L'archive ouverte pluridisciplinaire HAL, est destinée au dépôt et à la diffusion de documents scientifiques de niveau recherche, publiés ou non, émanant des établissements d'enseignement et de recherche français ou étrangers, des laboratoires publics ou privés. 
Bicarbonate concentration induces production of exopolysaccharides by Arthrospira platensis that mediate bio-flocculation and enhance flotation harvesting efficiency

\author{
J. B. Vergnes ${ }^{1}$, V. Gernigon ${ }^{1}$, P. Guiraud ${ }^{1,2}$, C. Formosa-Dague ${ }^{1,2,3^{*}}$
}

${ }^{1} \mathrm{TBI}$, Université de Toulouse, INSA, INRA, CNRS, Toulouse, France

${ }^{2}$ Fédération de recherche FERMAT, CNRS, Toulouse, France

${ }^{3}$ LAAS, Université de Toulouse, CNRS, Toulouse, France

*Corresponding author: formosa@insa-toulouse.fr

Mailing address: Toulouse Biotechnology Institute, 135 avenue de Rangeuil, 31077 Toulouse Cedex 4, France 


\section{Abstract}

Arthrospira platensis, or Spirulina, is a cyanobacterial species mainly exploited for its nutritional qualities and able to produce exopolysaccharides (EPS) under specific conditions. In this work we identify that the bicarbonate concentration is a key parameter that induces EPS production by the cells. Using flocculation/flotation harvesting experiments, in addition to atomic force microscopy to characterize the biophysical properties of EPS, we show that EPS produced by A. platensis cells form a soft, adhesive gel in the medium that forms aggregates in which cells are entrapped and thus bioflocculated. This results in the creation of microalgae flocs in which ascending microbubbles produced in flotation process get trapped, thus enhancing the efficiency of the microalgae separation from water. This interdisciplinary study provides new insights into culture conditions that positively influence the EPS production, while allowing to reach both a high final biomass concentration and a harvesting efficiency superior to $90 \%$.

Keywords: Arthrospira platensis; Exopolysaccharides; Bio-flocculation; Flotation; Atomic force microscopy 


\section{Introduction}

Arthrospira platensis, commonly known as Spirulina, is an edible filamentous cyanobacterium originally isolated from alkaline lakes in Africa, and presently cultivated in tropic, sub-tropic and tempered regions of the world. Because of its important nutritive qualities, this microalgae is now one of the most commercialized microalgae species ${ }^{1,2}$. Indeed, $A$. platensis is considered as the most valuable source of protein, as up to $70 \%$ of its biomass can be composed of this fraction, with a profile that includes the full range of essential amino acids ${ }^{3-5}$. The most valuable protein this cyanobacterium is able to produce is phycocyanin, which is used as a coloring agent in food and cosmetics ${ }^{6}$. Moreover, A. platensis is also a source of polyunsaturated fatty acids, vitamins (B12) and other pigments (chlorophyll A and carotene), and has been evaluated for therapeutic use. For instance, A. platensis features include hypolipidemic, hypoglycemic and anti-hypertensive properties, but also has antioxidant and microbial-modulating activities ${ }^{7}$.

Another important aspect of $A$. platensis is that this microalgae species is capable of producing extra-cellular exopolysaccharides (EPS). A wide range of microalgae (eukaryotic and cyanobacteria) produce EPS, which act as a protective layer around the cells to preserve them from unfavorable environmental conditions ${ }^{8}$. EPS from microalgae also have potential applications in industry and health ${ }^{9}$. For example, EPS can be used as thickening agents to alter water rheological properties, as heavy-metal removal agents for wastewater treatments, or even as food additives in the food industry 10-12. They also display several biological properties such as anti-inflammatory, anti-tumor, anti-viral, anti-parasitic and immunomodulatory activities ${ }^{9,12}$. For these reasons they have been the subject of many studies, with much effort focused on the determination of their composition, or the optimization of culture conditions that favor their production. In the case of the EPS produced by A. platensis, studies have shown that they are rich polymers composed of complex heteropolysaccharides with protein moieties ${ }^{13}$, and that temperature, light intensity and the cell's trophic mode could influence their production ${ }^{14,11}$. Another study also showed that their presence in water inhibits cell growth, which has implications in water recycling ${ }^{15}$. 
While A. platensis rich biomass and EPS are sought after for various applications, a limiting factor is their harvesting. Harvesting is usually a challenge in the case of microalgae because they grow at low concentrations, thereby resulting in a need to treat large volumes of water. This crucial step accounts for up to one third of the entire biomass production cost ${ }^{16}$. In the case of $A$. platensis, the most commonly used technique to harvest the cells is by filtration given their large size. Indeed, filtration tends to work better with larger microalgae rather than with smaller microalgae that can clog the membranes used in filtration ${ }^{17-19}$. While this technique is usually efficient for $A$. platensis cultures that produce no EPS, it has been shown that for $A$. platensis cultures that produce the EPS, these often clog the membranes, thus resulting in low efficiency with high operating costs ${ }^{20,21}$. Centrifugation can also be used in the case of $A$. platensis ${ }^{22}$, yet the operating costs of centrifugation are high due to the high energy input of this technique, but also the cell damage and loss resulting from the high-shear forces applied ${ }^{23,24}$. Flotation is a promising technique that has the advantages of having a low energyinput, reduced operating-costs and low space and equipment required. This technique is efficient to harvest cells cultivated in high-nutritive conditions if the cells are left to flocculate before the introduction of the bubbles ${ }^{25}$. In this case the efficiency of the process could also be enhanced by adding cationic floculants to the cell suspension $\left(\mathrm{CaCl}_{2}, \mathrm{MgCl}_{2}, \mathrm{FeCl}_{3}\right)^{25}$. However such added flocculants can then end up in the harvested biomass and interfere with the final product quality ${ }^{26}$. An interesting and sustainable alternative to this problem is natural auto- or bio-flocculation. For $A$. platensis, three cases of bio-flocculation have been reported. In these three cases, the same mechanism is described where bio-flocculation is directly induced by the accumulation of carbohydrates by the cells under nutrient stress conditions (phosphorous and nitrogen) or at high salinities, leading to an increase in their specific density ${ }^{27-29}$. However in these conditions, the nutrient deprivation results in reduced cell growth and biomass production.

The present study addressed the two important aspects in A. platensis, EPS production and harvesting. We show the direct influence of EPS on the recovery efficiency of the biomass using flocculation/flotation technique. For this we developed a culture strategy of $A$. platensis to assess the 
role of culture medium bicarbonate concentration on the production of EPS by the cells. Their implication in flocculation/flotation harvesting process were then evaluated in experiments at laboratory-scale. Finally, using an advanced atomic force microscopy ${ }^{30}$ imaging technique we characterized the biophysical properties of EPS to understand their role in flocculation. Altogether we describe an original bioflocculation mechanism and we provide culture conditions that allow for optimized biomass production and efficient harvesting.

\section{Material and Methods}

\section{Strain and culture conditions}

An Arthrospira platensis strain isolated for the Paracas lake in Peru was used in this study and cultivated in tap water containing the following: $\mathrm{Ca}(0.025 \mathrm{~g} / \mathrm{L}) ; \mathrm{Cl}(0.045 \mathrm{~g} / \mathrm{L}) ; \mathrm{K}_{2} \mathrm{O}(0.297 \mathrm{~g} / \mathrm{L}) ; \mathrm{NO}_{3}$ (1.779 g/L); Mg (0.012 g/L); Mn (0.230 g/L); Zn (0.461 mg/L); Cu (0.229 mg/L); B (0.229 mg/L); SO 4 $(0.583 \mathrm{~g} / \mathrm{L})$; complexed iron (micronutriFe, Prayon, Belgium, $0.003 \mathrm{~g} / \mathrm{L}), \mathrm{P}_{2} \mathrm{O}_{5}(0.178 \mathrm{~g} / \mathrm{L}$ ) and a variable concentration of $\mathrm{NaHCO}_{3}$ and $\mathrm{NaOH}$ to adjust the initial $\mathrm{pH}$ to 9.5. Cultures were achieved in $6 \mathrm{~L}$ poly(methyl methacrylate) photobioreactors and were continuously agitated by the gentle bubbling of atmospheric air ( $2 \mathrm{~L} / \mathrm{min}$ ). Illumination was provided by three submerged tubes containing warm white LEDs (BDL, vs-f600ww-12V-3528-10mm-2700K) delivering an irradiance of 280 or $350 \mu \mathrm{mol} v / \mathrm{m}^{2} / \mathrm{s}$ for a total of $916 \mathrm{~cm}^{2}$ of illuminated walls. The temperature of the culture was regulated at 30 or $35^{\circ} \mathrm{C}$ using an immersion heater (Scientax). The protocol used to cultivate the cells is described in Figure 1. Cultures were maintained in an inoculum culturing PBR (sub-cultures at an OD of 0.3 every week) at moderate cell growth conditions $\left(30^{\circ} \mathrm{C}, 280 \mu \mathrm{mol} v / \mathrm{m}^{2} / \mathrm{s}\right)$. For inoculating the experiments PBRs, $6 \mathrm{~L}$ from the inoculum culturing PBR were filtered on a $56 \mu \mathrm{m}$ sieve (Retsch, 60.131.000056); approximately $2 \mathrm{~g}$ of the retentate was then diluted in $6 \mathrm{~L}$ of new culture medium at different $\mathrm{NaHCO}_{3}$ concentrations. The culture in the experiments PBRs lasted 4 days in high cells growth conditions $\left(35^{\circ} \mathrm{C}\right.$, $350 \mu \mathrm{mol}_{v} / \mathrm{m}^{2} / \mathrm{s}$ ) and were monitored twice a day by measuring the optical density at $680 \mathrm{~nm}$. The 
$\mathrm{NaHCO}_{3}$ concentration was maintained constant during the four days of the culture by measuring the $\mathrm{pH}$ twice a day and adding $\mathrm{NaHCO}_{3}$. The $\mathrm{pH}$ measure was used in the following equation (1):

$$
[\mathrm{Bic}] \mathrm{i}+\Delta[\mathrm{Bic}]=\frac{[\mathrm{Ct}] \mathrm{i}+0.5 \times \Delta[\mathrm{Bic}]}{1+10^{\mathrm{pKa} 1-\mathrm{pHm}}+10^{\mathrm{pH}-\mathrm{pKa} 2}}
$$

Where $[B i c]$ and $[C t]$ are $\mathrm{HCO}_{3}{ }^{-}$concentration and $\mathrm{NaHCO}_{3}$ concentration at the beginning of the culture. $\Delta[B i c]$ is the variation of the bicarbonate ions concentration and is the unknown parameter of the equation. $p K a 1=6.3$ and $p K a 2=10.3$ are the two acid dissociation constants of the sodium bicarbonate in a water solution. $\mathrm{pHm}$ is the measured value of the $\mathrm{pH}$. This equation was solved with the Microsoft Excel solver after every measure and a quantity of $\mathrm{NaHCO}_{3}$ corresponding to the value obtained for $\Delta[B i c]$ was added to the culture medium.

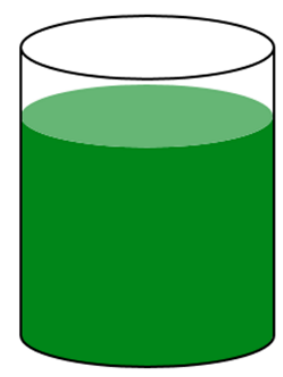

\section{Inoculum culturing PBR (6 L)}

[NaHCO3] $=0.25 \mathrm{~mol} / \mathrm{L}$ Moderate growth conditions

$\left(280 \mu \mathrm{mol}_{\mathrm{v}} / \mathrm{m}^{2} / \mathrm{s}, 30^{\circ} \mathrm{C}\right)$

Culture $1 \rightarrow 1$ week Culture $2 \rightarrow 4$ weeks Culture $3 \rightarrow 7$ weeks

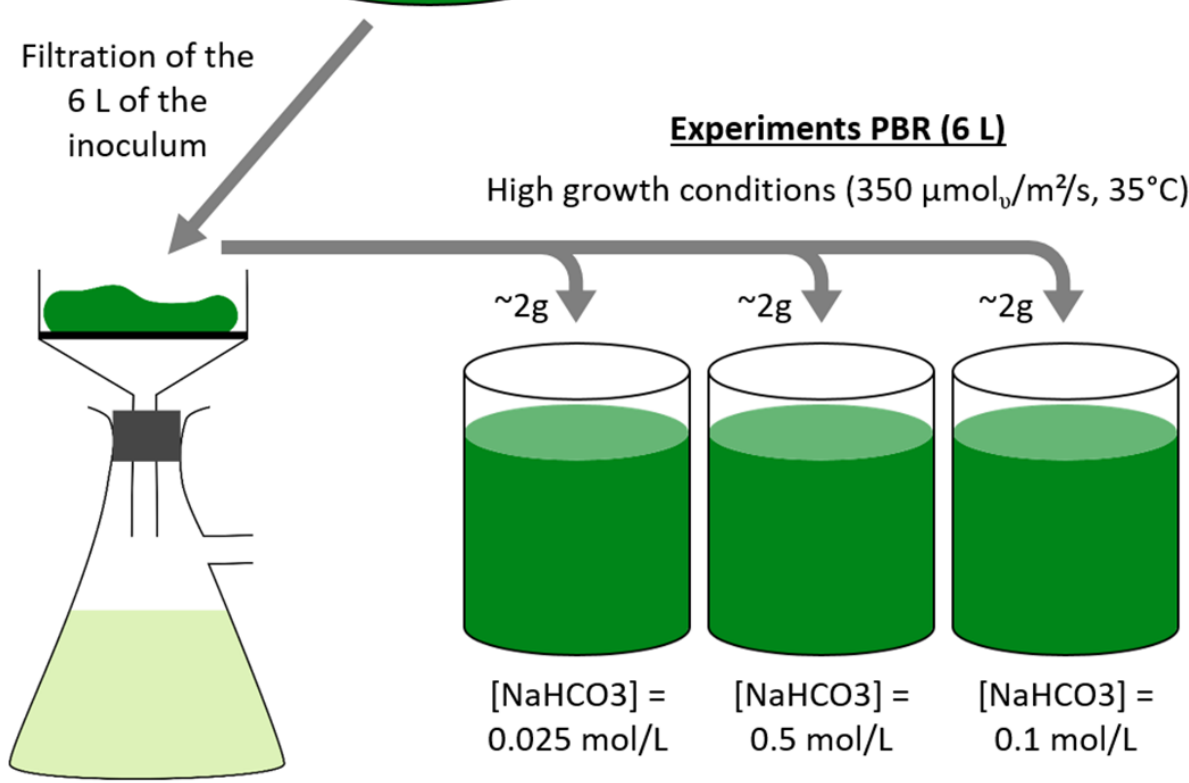

Figure 1. Schematic representation of the culturing protocol and conditions. A. platensis cells extracted from a maintaining tank where cell growth is low (outdoor lighting and temperature, in a $200 \mathrm{~L}$ tank) are cultured in a 6 L PBR in moderate growth conditions. This PBR is diluted every 5 days to an OD $(680 \mathrm{~nm})$ of 0.3 , before stationary phase is reached. To perform the experiments, cells cultured in the inoculum PBR during 1, 4 or 7 weeks (culture 1, 2 and 3 respectively) are harvested by filtration: $2 \mathrm{~g}$ of the cells are then inoculated into the experiments PBR at high growth conditions in culture medium containing different concentrations of $\mathrm{NaHCO}_{3}$. 


\section{Flocculation/flotation experiments}

A detailed presentation of the laboratory scale flotation experiments can be found in ${ }^{31,32}$. DAF experiments were performed in a Multiplace $\operatorname{Orchidis}^{T M}$ FTH3 Flottatest. Three flotation-test beakers were run simultaneously, in which $600 \mathrm{~mL}$ samples were collected from the algal cultures and added to each beaker. The depressurization at atmospheric pressure of $200 \mathrm{~mL}$ culture medium free of algae and saturated by air at 6 bars for 15 min induced the formation of microbubbles. The recycle ratio (pressurized culture medium volume/initial sample volume) was of $33 \%$. In each case, prior to depressurization, the cells were left to flocculate during 20 min under gentle mechanical mixing (100 rpm). Harvesting efficiency quantification is based on optical density measurements. The harvesting efficiency represents the quantity of algae floated compared to the quantity in the initial suspension: it was evaluated using the following equation:

$$
\mathrm{E}(\%)=\left(1-\frac{\mathrm{OD} a \mathrm{~V} a}{\mathrm{OD} i \mathrm{~V} i}\right) \times 100
$$

Where ODi and Vi are the initial optical density at $680 \mathrm{~nm}$ and the volume of algal suspension before flotation, $\mathrm{OD} a$ and $\mathrm{Va}$ are the optical density at $680 \mathrm{~nm}$ of the aqueous phase and the volume of the aqueous phase after injection of pressurized water.

\section{Filtration experiments}

Filtration experiments were performed in a $200 \mathrm{~mL}$ Amicon cell (Merck, 10402511) using an inox filter with a $10 \mu \mathrm{m}$ pore size (Negofiltres, stainless steel 316L). $1 \mathrm{~L}$ samples were collected from the algal cultures and added in a pressurized tank; filtration was then performed under 0.5 bars. The filtrate was collected in a beaker on a monitored scale and the weight of the filtrate was measured every $5 \mathrm{~s}$ for $900 \mathrm{~s}$. The filtrate density was of $1000 \mathrm{~g} / \mathrm{L}$ and the variation of the flow rate was calculated over time with the measure of the mass over time. 


\section{Optical and AFM imaging}

The optical images of $A$. platensis cells before flocculation/flotation experiments were directly obtained by sampling $1 \mathrm{~mL}$ of the cell suspension. These samples were then deposited on glass surfaces and allowed to stand for $30 \mathrm{~min}$ at room temperature. An Alcian blue staining was then used to color the EPS ${ }^{33}$. To this end, $1 \mathrm{~mL}$ of a solution made of $0.06 \%$ acetic acid and $0.03 \%$ of Alcian blue was deposited on the glass surfaces and allowed to stand for $15 \mathrm{~min}$. Glass surfaces were then immersed in distilled water for $15 \mathrm{~min}$ in order to remove the non-fixed staining. Finally images (resolution of $1024 \times 768$ pixels) were recorded at high magnification $(\times 50)$ using an inverted Axio Observer Z1 microscope (Zeiss). In order to evaluate the relative quantity of EPS from the optical images, images were analyzed using ImageJ software in order to determine the area of the image covered by EPS. For that, the color optical images were first split into the three color channels red, blue and green. As only the EPS are stained by the Alcian blue, both red and green channels were subtracted to the blue channel, to obtain an image of only the blue signal. This image was then binarized: on the binary image, a white pixel corresponds to blue and a dark pixel corresponds to the other colors on the initial image. The percentage of the area covered by EPS was calculated by extracting the number of white pixels on the binary image compared to the total number of pixels of the image. For AFM imaging, $1 \mathrm{~mL}$ of cell suspension was sampled and directly immobilized on polyethylenimine (PEI, Sigma P3143) coated glass slide prepared as previously described ${ }^{34}$. Briefly, freshly oxygen activated glass slides were covered by a $0.2 \% \mathrm{PEl}$ solution in deionized water and left for incubation overnight. Then the glass slides were rinsed with deionized water and dried under nitrogen. A total of $1 \mathrm{~mL}$ of cell suspension was then deposited on the PEI slides and allowed to stand for $30 \mathrm{~min}$ at room temperature. Images were recorded using the Quantitative Imaging ${ }^{\mathrm{TM}}$ mode available on the Nanowizard III AFM (Bruker). Multiparametric images were recorded with MLCT-BIO cantilevers (Bruker, nominal spring constant of $0.01 \mathrm{~N} / \mathrm{m}$ ) using an applied force of $1.0 \mathrm{nN}$, a constant approach/retract speed of $100 \mu \mathrm{m} / \mathrm{s}$, and a zrange of $3 \mu \mathrm{m}$. 


\section{Results and Discussion}

\section{Bicarbonate concentration in the growth medium influences EPS production}

Prior to initiating experimental conditions, all cells were cultured and maintained in an inoculum culturing PBR at low light intensity and moderate temperature $\left(30^{\circ} \mathrm{C}\right)$, with a bicarbonate concentration of $0.25 \mathrm{~mol} / \mathrm{L}(18.9 \mathrm{~g} / \mathrm{L})$, similar to Zarrouck's ${ }^{35}$ medium commonly used to cultivate $A$. platensis. Cells were then filtered and inoculated in three experiments PBR containing culture medium with bicarbonate concentrations of $0.025 \mathrm{~mol} / \mathrm{L}(2.1 \mathrm{~g} / \mathrm{L}, \mathrm{PBR} 1), 0.05 \mathrm{~mol} / \mathrm{L}(4.2 \mathrm{~g} / \mathrm{L}, \mathrm{PBR} 2)$ or $0.1 \mathrm{~mol} / \mathrm{L}$ (8.4 g/L, PBR3) (Figure 1). These concentrations of bicarbonate are lower than the ones found in the literature ${ }^{13-15,28}$. Because $A$. platensis grows in alkaline waters, the amount of dissolved $\mathrm{CO}_{2}$ is low, and so the bicarbonate is added to be used as a source of carbon, and assimilated due to the energy they capture from light. As bicarbonate ions are consumed by the cells, hydroxide ions are released into the medium, thereby increasing the $\mathrm{pH}$ over the course of the culture ${ }^{36}$. To avoid this, and to assess only the role of the bicarbonate concentration on the EPS production, we chose to perform our cultures at a $\mathrm{pH}$ of 9 , and maintain the bicarbonate concentration constant over 4 days of culture in the experiments PBRs. Towards this end, the $\mathrm{pH}$ of the culture medium was measured twice a day, which indicated the quantity of bicarbonate consumed by the cells, which could then be compensated by adding bicarbonate into the medium (the detailed procedure is found in the materials and methods).

Characterization of the EPS produced by A. platensis have been the subject of considerable study ${ }^{13,37}$. Previous studies have shown that the EPS consist of heteropolysaccharides with protein moieties, and that the polysaccharidic fraction is composed of neutral sugars and uronic acids, in different proportions depending on the strains and the culture conditions used. EPS were also shown to form aggregates that could be detected using histological staining with dyes such as Alcian blue that reacts with acidic polysaccharides ${ }^{38,39}$. We selected this technique to qualitatively evaluate the effects of bicarbonate concentration on the production of EPS in samples taken from the three experiments PBRs of culture 1 (1 week in inoculating PBR). Our results, presented in Figure 2, show that no EPS could be detected in cells grown at the lowest bicarbonate concentration (Fig. 2a). However, in the 
case of cells grown with bicarbonate concentrations of 0.05 and $0.1 \mathrm{~mol} / \mathrm{L}$ (Fig. $2 \mathrm{c}$ and d), aggregated EPS could be detected around cells and the quantity was positively correlated to the concentration of bicarbonate. To relatively quantify the observed differences in EPS concentrations, we developed an original image treatment strategy allowing us to measure on these images the area covered by the EPS. Toward this end, the blue signal only was first extracted from each image: the blue images were then converted into binary images (Fig. 2b, $d$ and f), where white pixels correspond to blue and dark pixels correspond to the other colors on the initial images. Then, knowing the pixel resolution of our images, we could extract the number of white pixels and calculate the percentage of the area covered by the EPS. The results of these analyses, performed in each case on 7 different images for each conditions, are presented in Fig.2g. At low $\mathrm{NaHCO}_{3}$ concentration, the mean area covered by EPS in the recorded images is of $5.5 \pm 2.3 \%$, whereas it increases to $8.2 \pm 1.0 \%$ at a concentration of 0.05 $\mathrm{mol} / \mathrm{L}$, and to $14.1 \pm 0.7 \%$ at a concentration of $0.1 \mathrm{~mol} / \mathrm{L}$ (differences are significant at a $\mathrm{p}$-value < 0.05, Mann-Whitney test). These analyses then allow us to quantitatively show the increase in EPS production with the bicarbonate concentration, and to show that their relative quantity depends on the bicarbonate concentration. This observation proves that the bicarbonate concentration in the culture medium influences the production of EPS in our culture conditions, and that the more bicarbonate was present, the more EPS could be produced. This is the first time to our knowledge that this factor is showed to influence EPS production in A. platensis, and more generally in cyanobacteria. Previous studies on this particular species have showed that factors influencing their production were light, temperature and the cell's trophic mode ${ }^{14,11}$. More globally for cyanobacteria, other factors have been identified such as phosphate, nitrogen and sulfate deprivation, or $\mathrm{pH}$ and aeration ${ }^{8}$. The positive influence of carbon availability on the EPS production that we observe here could be explained by the fact that cells use the carbon needed for their growth, and, in favorable conditions (high temperature and high light intensity), they use the remaining available carbon to produce EPS. 


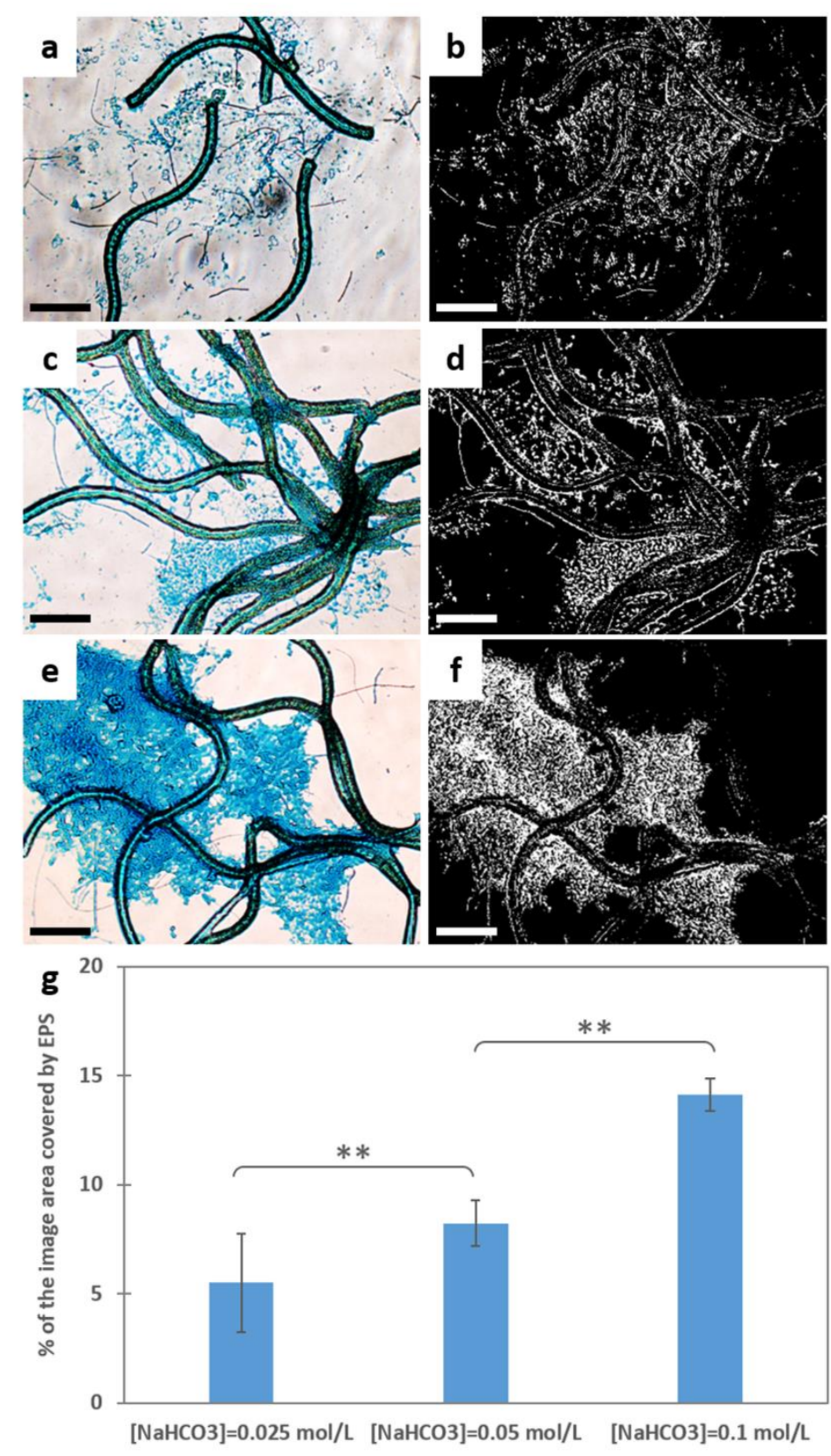

Figure 2. Optical imaging of EPS produced by A. platensis grown at different $\mathrm{NaHCO}_{3}$ concentrations. Optical image of $A$. platensis cells from culture 1 , grown at a $\mathrm{NaHCO}_{3}$ concentration of (a) $0.025 \mathrm{~mol} / \mathrm{L}$, (c) $0.05 \mathrm{~mol} / \mathrm{L}$ and (e) $0.1 \mathrm{~mol} / \mathrm{L}$. The blue aggregates correspond to Alcian blue stained polysaccharides. Images in (b), (d) and (f) are the binary images of the blue signals from the images respectively in (a), (c) and (e). Scale-bar corresponds to $50 \mu \mathrm{m}$. (g) Histogram showing the average percentage of the area covered by EPS for $A$. platensis cells cultured at the different $\mathrm{NaHCO}_{3}$ concentrations. The stars indicate that the differences observed are significant at a $p$-value $<0.05$ (Mann-Whitney test).

We next wanted to understand the impact of bicarbonate concentration on cell growth. Indeed, in phosphate or nitrogen deprived conditions that also favor EPS production, cells do not grow and thus a balance must be met between EPS production and biomass. To evaluate if a low bicarbonate 
concentration also has impacts on the biomass production, we followed the cultures over 4 days using different concentrations, in 3 different cultures. The results, presented in figure 3 , show the changes in biomass concentration over time for the 3 different cultures (Fig. 3a, b and c). The qualitative observation of these 3 cultures suggests that the $\mathrm{NaHCO}_{3}$ concentration does not have a significant impact on the growth, even if a small effect can be observed in the case of the first culture. To quantitatively assess this point, the average growth factors were calculated in each case and the histograms are presented in Fig. 3d. We found that the average growth factor obtained for each bicarbonate concentrations over the 3 cultures was similar, thus indicating that even at the lowest bicarbonate concentration, the growth rate of the cells is not affected. Moreover higher $\mathrm{NaHCO}_{3}$ concentrations were also used (up to $0.25 \mathrm{~mol} / \mathrm{L}$ ) which also has no effects on the cell growth rate (data not showed). One interesting note however is that while the growth rate does not vary with the bicarbonate concentration, the final biomass concentration reached decreases in cultures 2 and 3 compared to culture 1 . Indeed, in culture 1 , the average final biomass concentration is of approximately $1400 \mathrm{mg} / \mathrm{L}$, while in culture 2 it is of $1230 \mathrm{mg} / \mathrm{L}$ and of $925 \mathrm{mg} / \mathrm{L}$ in culture 3 , even if the initial biomass concentrations are almost identical. This can be explained by the time cells spent in the inoculum culturing PBR before being used for experiments (Figure 1). In this PBR, bicarbonate concentration is high $(18.9 \mathrm{~g} / \mathrm{L})$, but temperature and light intensity are moderate. Previous work by Trabelsi et al. indicated that $30^{\circ} \mathrm{C}$ with low light intensity still induces the production of EPS by the cells, but at low quantity ${ }^{14}$. Thus we can suppose that after one week in this PBR (culture 1), no or low quantity of EPS were produced, but that after 4 (culture 2) and 7 weeks (culture 3), cells could have produced more EPS. Thus, when filtrating this biomass to inoculate the experiments PBRs, EPS are also retained and inoculated. The biomass in fact inoculated is lower, which leads to lower biomass production in the end. Moreover, the presence of EPS in the medium have been shown to inhibit the cell growth ${ }^{15}$. These two reasons may explain why the final biomass concentration reached in the experiments PBRs decreases with the time the inoculated biomass spent in the inoculum culturing PBR. Therefore, in the range of concentrations tested here, we show that the more bicarbonate present in 
the medium, the more EPS are produced by the cells in optimal conditions of light and temperature. Another important point is that even at low bicarbonate concentration $(2.1 \mathrm{~g} / \mathrm{L})$, cell growth is unaffected, if this concentration is maintained over the culture. Using higher NaHCO3 concentrations thus only increases the quantity of EPS produced by the cells and has no impact on their growth. But what about the effects of EPS production on harvesting?
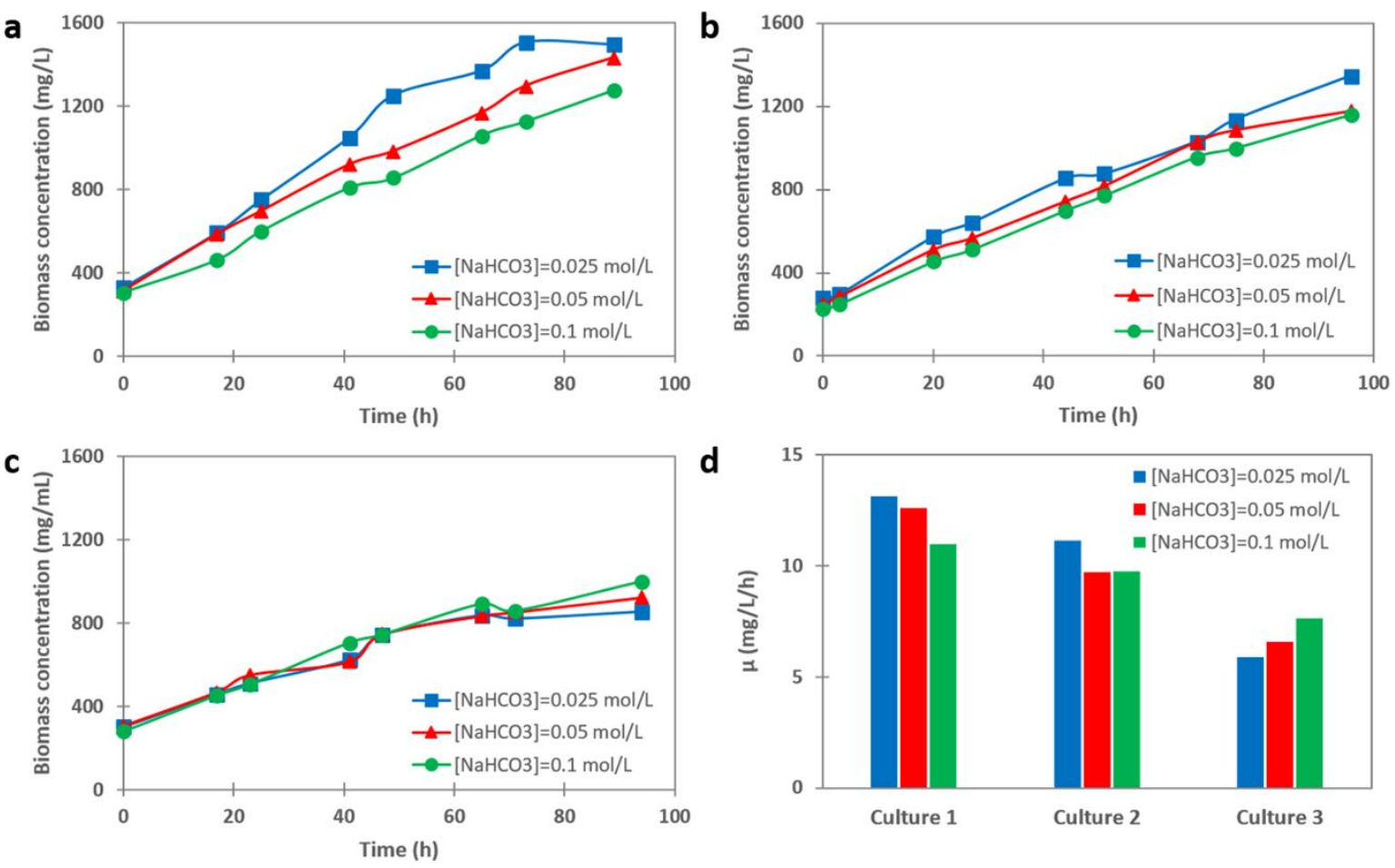

Figure 3. Growth rate of $A$. platensis under different $\mathrm{NaHCO} 3$ concentrations. Biomass concentration as a function of time for (a) Culture 1 (1 week of culture in the inoculum PBR), (b) Culture 2 (4 weeks of culture in the inoculum PBR) and (c) Culture 3 (7 weeks of culture in the inoculum PBR) at a $\mathrm{NaHCO}_{3}$ concentration of $0.025 \mathrm{~mol} / \mathrm{L}$ (blue line), $0.05 \mathrm{~mol} / \mathrm{L}$ (red line) and $0.1 \mathrm{~mol} / \mathrm{L}$ (green line). (d) Histogram showing the growth factor $\mu(\mathrm{mg} / \mathrm{L} / \mathrm{h})$ of the 3 different cultures at the different $\mathrm{NaHCO}_{3}$ concentrations.

\section{The presence of EPS has a positive influence on the flocculation/flotation efficiency}

In an effort to determine if the EPS had an effect on harvesting, we performed flocculation/flotation harvesting experiments the 4 days of culture for each bicarbonate concentration and each culture. The results are presented in figure 4, where figure 4a shows images extracted from a video recording of the flocculation/flotation experiment in the case of the three experiments PBRs of culture 1. The full video recording is available in Supp Data 1. In these images, the flotation-test 
beakers are first filled with the cells grown at the different bicarbonate concentrations and left to flocculate during 20 minutes with gentle agitation. After this time, microbubbles are added (with increasing volume) and left for 10 minutes. The images show that in the case of low bicarbonate concentration $(0.025 \mathrm{~mol} / \mathrm{L}$, left flotation-test beaker), only a small fraction of the cells float to the surface and the treated phase remains intense green. For the intermediate bicarbonate concentration ( $0.05 \mathrm{~mol} / \mathrm{L}$, middle flotation-test beaker), a large fraction of the cells accumulate at the surface, while the treated phase contains cells, as judged by the less intense green color still visible. Finally for the highest bicarbonate concentration $(0.1 \mathrm{~mol} / \mathrm{L}$, right flotation-test beaker), most of the cells have reached the surface, and the treated phase is uncolored. The treated phase was then filtered in each case; the remaining filters obtained in the case of culture 1 are showed in Figure $4 \mathrm{~b}$. We observe that for bicarbonate concentrations of $0.025 \mathrm{~mol} / \mathrm{L}$ and $0.05 \mathrm{~mol} / \mathrm{L}$, cells remained on the filter (up and middle filters), and that in the case of a bicarbonate concentration of $0.1 \mathrm{~mol} / \mathrm{L}$, no cells are visible. However in this case, a beige layer can be observed on the filter, which could correspond to the retention of EPS on the filter.

Finally, the efficiencies of harvesting were calculated using equation (2) by measuring the optical density in the treated phases; the results are presented in Fig. 4c. We found that in the case of the first culture ( 1 week in the inoculum preparing PBR), the efficiency at low bicarbonate concentration reaches only $7.4 \%$, while for the higher concentrations it is of $85.1 \%$ and $97.4 \%$. Further increasing the $\mathrm{NaHCO}_{3}$ concentration, up to $0.25 \mathrm{~mol} / \mathrm{L}$, did not further increase the harvesting efficiency (data not showed). In the case of the first culture, where no EPS coming from the inoculum are present, only the EPS produced during the 4 days culture are present, and thus only their effect on the flocculation/flotation is assessed. It seems thus that the EPS production is directly related to the flocculation/flotation efficiency, as the more EPS produced, the more efficient the harvesting. For cultures 2 and 3 , an important point is that at low bicarbonate concentration, the harvesting efficiency is increased in culture 2 to $41.3 \%$ and to $86.6 \%$ in culture 3, whereas the cells in this condition do not produce EPS. As discussed previously, this can be explained by the fact that EPS produced in the 
inoculum culturing PBR are transferred into the experiments PBRs; their presence enhances flocculation/flotation efficiency, even if they are not produced by the cells directly during the culture in the experiments PBRs. This further shows the direct correlation between the EPS and the flocculation/flotation efficiency, as EPS have a positive influence on the harvesting efficiency. To further show this correlation, we performed filtration experiments in the case of culture 1 (Supp. Data 2). We show that for low-bicarbonate concentrated cells, both the filtered biomass and the filtration flow rate are high. By increasing the bicarbonate concentration in the medium, these two measured parameters decreased. This finding is in accordance with the literature, where the EPS present can clog the membranes used, which results in low filtration efficiency ${ }^{15,20}$. So while the positive influence of EPS on flocculation/flotation harvesting is here clearly demonstrated, we next wanted to identify the basis of this positive influence.

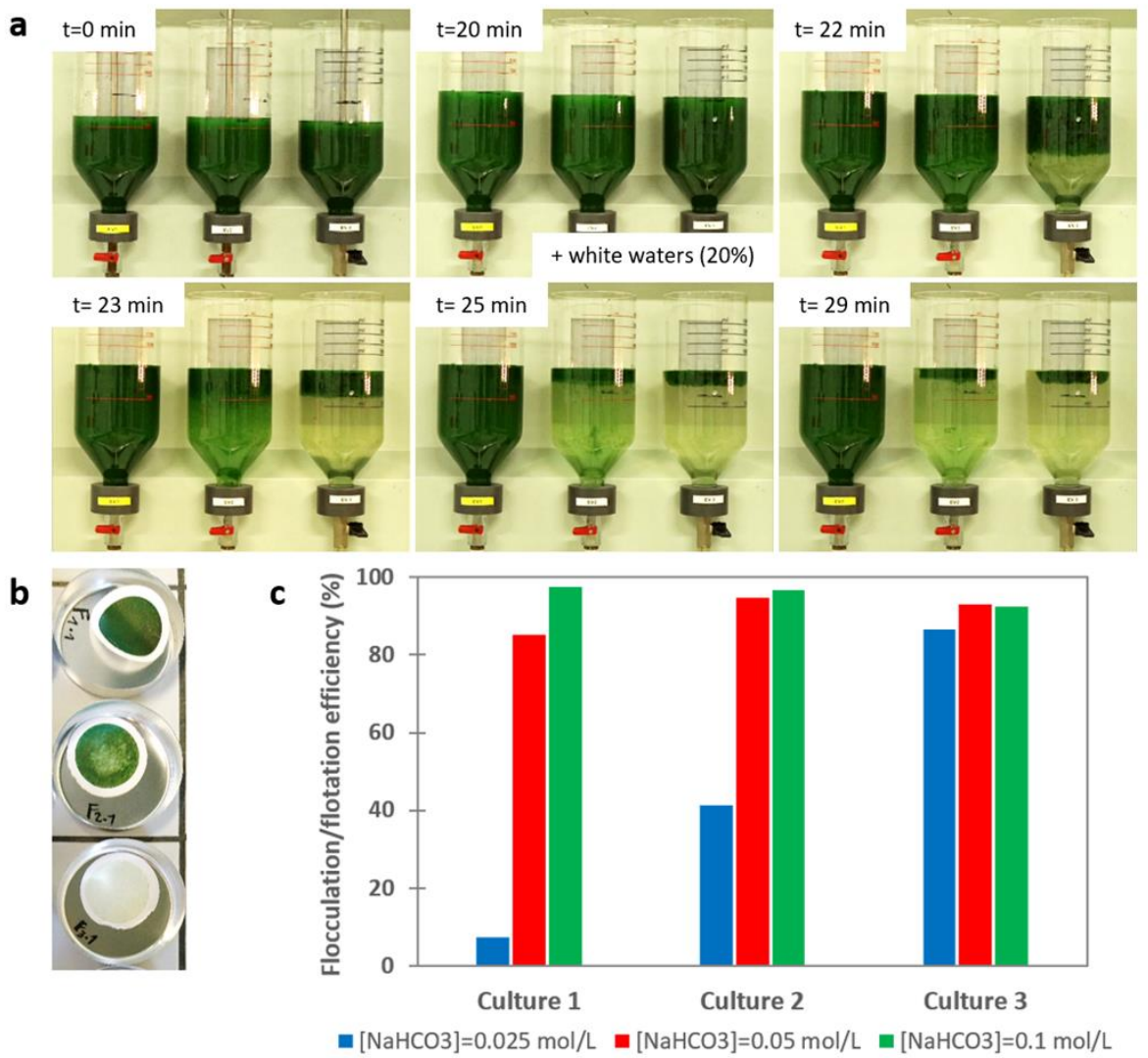

Figure 4. Flocculation/flotation harvesting of $A$. platensis at different $\mathrm{NaHCO}_{3}$ concentrations. (a) Images extracted from a video recording of the flocculation/flotation of the cells from Culture 1 in a laboratory-scale DAF device. The left flotation-test beaker contains cells grown at a $\mathrm{NaHCO}_{3}$ concentration of $0.025 \mathrm{~mol} / \mathrm{L}$, the middle flotation-test beaker contains cells grown at a $\mathrm{NaHCO}_{3}$ concentration of $0.05 \mathrm{~mol} / \mathrm{L}$, and the right flotation-test beaker contains cells grown at a $\mathrm{NaHCO}_{3}$ 
concentration of $0.1 \mathrm{~mol} / \mathrm{L}$. Prior to white waters injection, the cells are left to flocculate during $20 \mathrm{~min}$ under agitation. (b) Photograph of filters used to filtrate the treated phase of the cells from Culture 1 after flocculation/flotation. The top filter corresponds to the treated phase of cells grown at a $\mathrm{NaHCO}_{3}$ concentration of $0.025 \mathrm{~mol} / \mathrm{L}$, the middle filter corresponds to the treated phase of cells grown at a $\mathrm{NaHCO}_{3}$ concentration of $0.05 \mathrm{~mol} / \mathrm{L}$, and the bottom filter corresponds to the treated phase of cells grown at a $\mathrm{NaHCO} 3$ concentration of $0.1 \mathrm{~mol} / \mathrm{L}$. (c) Histogram showing the flocculation/flotation efficiency of the cells from the 3 different cultures at the different $\mathrm{NaHCO}_{3}$ concentrations.

\section{EPS induce $A$. platensis bio-flocculation}

EPS, and more globally all the algal organic matter (AOM) excreted by microalgae cells during their growth that include proteins, polysaccharides, nucleic acids, lipids and small molecules, can be involved in microalgae flocculation. Several studies have showed the influence of AOM on induced flocculation (alkaline flocculation or flocculation induced by chitosan or cationic polymers) in a positive or negative way, as for example demonstrated for Chlorella vulgaris cells ${ }^{40,41}$. However, the direct role of EPS in bio-flocculation has never been described for any microalgae species. For A. platensis, the only studies reporting cases of bio-flocculation describe that nutrient deprived conditions or high salinity can trigger an accumulation of carbohydrates in cells, which changes the density of the cells and allows their flocculation and settling. It is clear in these studies that no EPS are responsible for the flocculation observed ${ }^{25,27,29,28}$. In our study, the cells are not nutrient-deprived or grown at high salinities. As such, cells do not accumulate carbohydrates, therefore the mechanism previously described cannot apply to our case. Thus our hypothesis, given our harvesting results showing the direct link between EPS and flocculation/flotation efficiency, is that the EPS induces bio-flocculation of the cells in our culture conditions, thus enhancing the efficiency of cell separation by flotation.

To verify this hypothesis we performed atomic force microscopy (AFM) imaging experiments on the EPS produced by the cells. We used an advanced imaging technique, called quantitative imaging, in which a bare tip is pushed toward the sample and retracted at high-speed over a matrix of points on the sample. Recorded force curves are then analyzed in different ways, so that correlated images of the structure, adhesion, and mechanics of the samples can be obtained simultaneously ${ }^{42}$. Such correlated images of isolated aggregates of EPS produced by A. platensis cells from culture 1, and grown at a bicarbonate concentration of $0.1 \mathrm{~mol} / \mathrm{L}$, are presented in figure 5 . These images show that 
the EPS produced form a thick layer that reaches $4 \mu \mathrm{m}$ in height, as shown by the cross-section (Fig $5 \mathrm{~b}$ ) taken along the grey line on the height image presented in Fig. 5a. The image in Fig 5c. shows the same EPS structure but from the nanomechanical point of view. To obtain this image, the force curves obtained were analyzed using a theoretical model, the Hertz model ${ }^{43}$, that allows extracting the Young modulus $(\mathrm{Ym})$ of the sample. Ym refers to the resistance of the sample to the compression exerted by the tip at a given applied force. The lower the Ym value, the softer the sample. The nanomechanical image (Fig. 5c) shows that EPS is a rather soft structure (pixels corresponding to EPS are dark on the image), which is further confirmed by the quantification of the Ym values plotted in Fig. $5 d$ ( $n=4976$ force curves on 3 isolated EPS aggregates), yielding values of $19.1 \pm 9.8 \mathrm{kPa}$. These values are consistent with $\mathrm{Ym}$ values reported for other types of extra-cellular organic matter from bacterial cells ${ }^{44}$, and demonstrate that EPS from A. platensis form a soft gel-like structure surrounding the cells. Figure $5 e$ is the adhesion image and represents the adhesive behavior of the EPS, which is assessed by measuring the interactions between the tip and the sample for each force curves; bright pixels on the image correspond to a high force interaction meaning that the sample is adhesive. It is then clear on this image that EPS, forming a soft gel layer around the cells, are also adhesive (pixels corresponding to EPS are bright on the image), based on the adhesion values obtained: $66.5 \pm 34.4 \mathrm{pN}$ ( $\mathrm{n}=8059$ force curves on 3 isolated EPS aggregates) (Fig. 5f). These values are comparable with other type of extra-cellular polymers ${ }^{44}$. Thus these results validate our hypothesis that EPS are responsible of the bio-flocculation of the cells. Indeed, our nanoscale observations show that EPS form a soft and sticky gel in which the cells are enmeshed, resulting in their flocculation. This is also consistent with the observations from Alcian blue staining that showed that cells are indeed entrapped in EPS aggregates (Fig. $2 b$ and c). We thus describe here an original bio-flocculation mechanism in A. platensis, where the EPS produced by the cells under specific culture conditions stick to the cells and aggregate them in flocs. As a result, microbubbles produced in flotation process trap microalgae flocs, thereby enhancing the harvesting efficiency. 

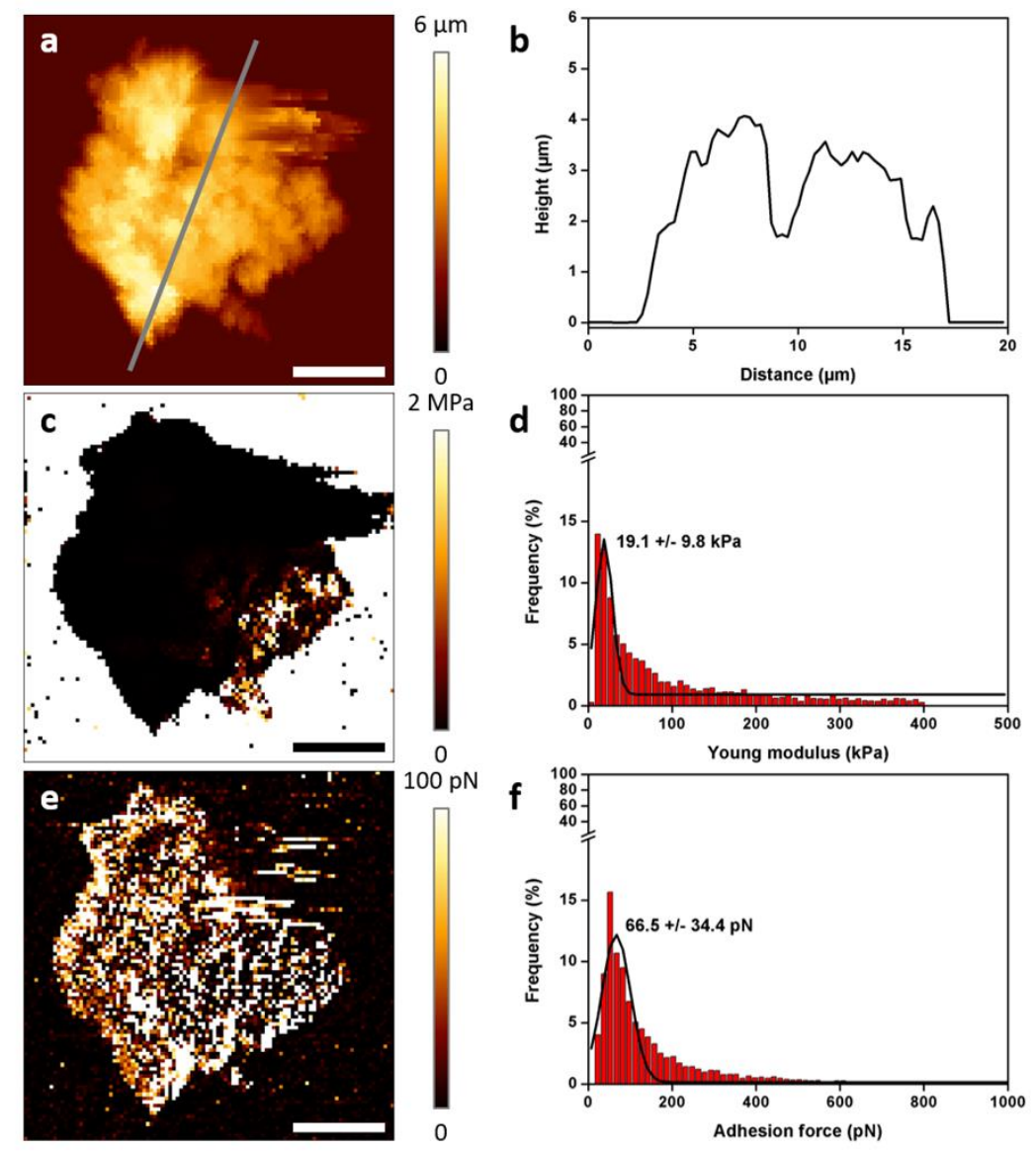

Figure 5. AFM multiparametric imaging of $A$. platensis cells before harvesting. (a) AFM height image of an isolated aggregate of EPS and (b) cross-section taken along the grey line in (a). (c) Corresponding nanomechanical image of the isolated EPS aggregate presented in (a) and (d) histogram presenting the distribution of the Young modulus values obtained on 3 different isolated aggregates of EPS. (e) Corresponding adhesion image of the isolated EPS aggregate presented in (a) and (e) histogram presenting the distribution of the adhesion values obtained on 3 different isolated aggregates of EPS. Scale-bars correspond to $5 \mu \mathrm{m}$.

\section{Conclusions}

The work presented here identified a new factor influencing the EPS production in A. platensis.

While temperatures superior to $30^{\circ} \mathrm{C}$ and intense light are needed, the concentration in bicarbonate in the culture medium and thus the availability of carbon, induced the production of EPS by the cells. In view of our observations within the concentration range tested, the more carbon available, the more EPS could be produced. We then showed that the induced production of EPS had a key role in harvesting. Indeed, they form a soft and adhesive gel that form aggregates in which cells are entrapped and thus bio-flocculated, without requiring any addition of external flocculants. As a result, 
microbubbles produced in flotation process were trapped in these microalgae flocs, which then allowed for their efficient separation from the water. We provide here culture conditions in which high biomass and EPS production are possible, and for which a sustainable harvesting by flocculation/flotation results in separation efficiencies superior to $90 \%$. These culture conditions can also be adapted for filtration harvesting. If filtration harvesting is preferred, we show that at a low bicarbonate concentration a high biomass production can be reached without production of EPS, which can clog filtration membranes. Further study is now required to characterize the EPS production for $A$. platensis in the conditions we describe and determine the structure-function relationship of the different fractions of the EPS. More work should also be performed to investigate if this original EPS production and bio-flocculation mechanism can also apply to different species of microalgae that are of industrial interest.

\section{Acknowledgements}

C. F.-D. is a postdoctoral researcher supported by the AgreenSkills fellowship programme, which has received funding from the EU's Seventh Framework Programme under grant agreement No. FP7609398 (AgreenSkills+contract). This work has been supported by the ANR JCJC project FLOTALG to C. F.-D. (ANR-18-CE43-0001-01) and by the project INSPIRO, co-funded by the EU-FEDER (Fonds Européen de Développement Régional), the Région Occitanie, France and INSA-LISBP.

\section{Author contribution}

C. F.-D. and P. G. conceived the project. C. F.-D., J.-B. V. and V. G. conceived the experimental work. J.-B. V. performed the experiments. All authors discussed and interpreted the results. C. F.-D. wrote the manuscript. All authors reviewed, contributed to and approved the final manuscript. 


\section{Supporting information}

- Video recording of flocculation/flotation harvesting of $A$. platensis

- Filtration harvesting of $A$. platensis at different $\mathrm{NaHCO}_{3}$ concentrations

\section{References}

(1) Kim, C.-J.; Jung, Y.-H.; Oh, H.-M. Factors Indicating Culture Status during Cultivation of Spirulina (Arthrospira) Platensis. J. Microbiol. Seoul Korea 2007, 45 (2), 122-127.

(2) Raja, R.; Coelho, A.; Hemaiswarya, S.; Kumar, P.; Carvalho, I. S.; Alagarsamy, A. Applications of Microalgal Paste and Powder as Food and Feed: An Update Using Text Mining Tool. Beni-Suef Univ. J. Basic Appl. Sci. 2018, 7 (4), 740-747. https://doi.org/10.1016/j.bjbas.2018.10.004.

(3) Dillon, J. C.; Phuc, A. P.; Dubacq, J. P. Nutritional Value of the Alga Spirulina. World Rev. Nutr. Diet. 1995, 77, 32-46.

(4) Rodrigues, M. S.; Ferreira, L. S.; Converti, A.; Sato, S.; de Carvalho, J. C. M. Influence of Ammonium Sulphate Feeding Time on Fed-Batch Arthrospira (Spirulina) Platensis Cultivation and Biomass Composition with and without PH Control. Bioresour. Technol. 2011, 102 (11), 6587-6592. https://doi.org/10.1016/j.biortech.2011.03.088.

(5) de la Jara, A.; Ruano-Rodriguez, C.; Polifrone, M.; Assunçao, P.; Brito-Casillas, Y.; Wägner, A. M.; Serra-Majem, L. Impact of Dietary Arthrospira (Spirulina) Biomass Consumption on Human Health: Main Health Targets and Systematic Review. J. Appl. Phycol. 2018, 30 (4), 2403-2423. https://doi.org/10.1007/s10811-018-1468-4.

(6) Spolaore, P.; Joannis-Cassan, C.; Duran, E.; Isambert, A. Commercial Applications of Microalgae. J. Biosci. Bioeng. 2006, 101 (2), 87-96. https://doi.org/10.1263/jbb.101.87.

(7) Finamore, A.; Palmery, M.; Bensehaila, S.; Peluso, I. Antioxidant, Immunomodulating, and Microbial-Modulating Activities of the Sustainable and Ecofriendly Spirulina. Oxid. Med. Cell. Longev. 2017, 2017, 3247528. https://doi.org/10.1155/2017/3247528. 
(8) Pereira, S.; Zille, A.; Micheletti, E.; Moradas-Ferreira, P.; De Philippis, R.; Tamagnini, P. Complexity of Cyanobacterial Exopolysaccharides: Composition, Structures, Inducing Factors and Putative Genes Involved in Their Biosynthesis and Assembly. FEMS Microbiol. Rev. 2009, 33 (5), 917-941. https://doi.org/10.1111/j.1574-6976.2009.00183.x.

(9) Markou, G.; Nerantzis, E. Microalgae for High-Value Compounds and Biofuels Production: A Review with Focus on Cultivation under Stress Conditions. Biotechnol. Adv. 2013, 31 (8), 15321542. https://doi.org/10.1016/j.biotechadv.2013.07.011.

(10) Raposo, M. F. de J.; de Morais, R. M. S. C.; Bernardo de Morais, A. M. M. Bioactivity and Applications of Sulphated Polysaccharides from Marine Microalgae. Mar. Drugs 2013, 11 (1), 233-252. https://doi.org/10.3390/md11010233.

(11) Trabelsi, L.; Ben Ouada, H.; Zili, F.; Mazhoud, N.; Ammar, J. Evaluation of Arthrospira Platensis Extracellular Polymeric Substances Production in Photoautotrophic, Heterotrophic and Mixotrophic Conditions. Folia Microbiol. (Praha) 2013, 58 (1), 39-45. https://doi.org/10.1007/s12223-012-0170-1.

(12) Delattre, C.; Pierre, G.; Laroche, C.; Michaud, P. Production, Extraction and Characterization of Microalgal and Cyanobacterial Exopolysaccharides. Biotechnol. Adv. 2016, 34 (7), 1159-1179. https://doi.org/10.1016/j.biotechadv.2016.08.001.

(13) Trabelsi, L.; M'sakni, N. H.; Ben Ouada, H.; Bacha, H.; Roudesli, S. Partial Characterization of Extracellular Polysaccharides Produced by Cyanobacterium Arthrospira Platensis. Biotechnol. Bioprocess Eng. 2009, 14 (1), 27-31. https://doi.org/10.1007/s12257-008-0102-8.

(14) Trabelsi, L.; Ben Ouada, H.; Bacha, H.; Ghoul, M. Combined Effect of Temperature and Light Intensity on Growth and Extracellular Polymeric Substance Production by the Cyanobacterium Arthrospira Platensis. J. Appl. Phycol. 2009, 21 (4), 405-412. https://doi.org/10.1007/s10811008-9383-8. 
(15) Depraetere, O.; Pierre, G.; Noppe, W.; Vandamme, D.; Foubert, I.; Michaud, P.; Muylaert, K. Influence of Culture Medium Recycling on the Performance of Arthrospira Platensis Cultures. Algal Res. 2015, 10, 48-54. https://doi.org/10.1016/j.algal.2015.04.014.

(16) Molina Grima, E.; Belarbi, E. H.; Acien Fernandez, F. G.; Robles Medina, A.; Chisti, Y. Recovery of Microalgal Biomass and Metabolites: Process Options and Economics. Biotechnol Adv 2003, $20(7-8), 491-515$.

(17) Rossi, N.; Petit, I.; Jaouen, P.; Legentilhomme, P.; Derouiniot, M. Harvesting of Cyanobacterium Arthrospira Platensis Using Inorganic Filtration Membranes. Sep. Sci. Technol. 2005, 40 (15), 3033-3050.

(18) Rossi, N.; Jaouen, P.; Legentilhomme, P.; Petit, I. Harvesting of Cyanobacterium Arthrospira Platensis Using Organic Filtration Membranes. Food Bioprod. Process. 2004, 82 (3), 244-250.

(19) Drexler, I. L. C.; Yeh, D. H. Membrane Applications for Microalgae Cultivation and Harvesting: A Review. Rev. Environ. Sci. Biotechnol. 2014, 13 (4), 487-504. https://doi.org/10.1007/s11157014-9350-6.

(20) Rossi, N.; Derouiniot-Chaplain, M.; Jaouen, P.; Legentilhomme, P.; Petit, I. Arthrospira Platensis Harvesting with Membranes: Fouling Phenomenon with Limiting and Critical Flux. Bioresour. Technol. 2008, 99 (14), 6162-6167. https://doi.org/10.1016/j.biortech.2007.12.023.

(21) Barros, A. I.; Gonçalves, A. L.; Simões, M.; Pires, J. C. M. Harvesting Techniques Applied to Microalgae: A Review. Renew. Sustain. Energy Rev. 2015, 41, 1489-1500. https://doi.org/10.1016/j.rser.2014.09.037.

(22) Morist, A.; Montesinos, J. L.; Cusidó, J. A.; Gòdia, F. Recovery and Treatment of Spirulina Platensis Cells Cultured in a Continuous Photobioreactor to Be Used as Food. Process Biochem. 2001, 37 (5), 535-547. https://doi.org/10.1016/\$0032-9592(01)00230-8.

(23) Pragya, N.; Pandey, K. K.; Sahoo, P. K. A Review on Harvesting, Oil Extraction and Biofuels Production Technologies from Microalgae. Renew. Sustain. Energy Rev. 2013, 24, 159-171. https://doi.org/10.1016/j.rser.2013.03.034. 
(24) Garg, S.; Wang, L.; Schenk, P. M. Flotation Separation of Marine Microalgae from Aqueous Medium. Sep. Purif. Technol. 2015, 156 (Part 2), 636-641. https://doi.org/10.1016/j.seppur.2015.10.059.

(25) Kim, S. G.; Choi, A.; Ahn, C. Y.; Park, C. S.; Park, Y. H.; Oh, H. M. Harvesting of Spirulina Platensis by Cellular Flotation and Growth Stage Determination. Lett. Appl. Microbiol. 2005, 40 (3), 190194.

(26) Vandamme, D.; Foubert, I.; Muylaert, K. Flocculation as a Low-Cost Method for Harvesting Microalgae for Bulk Biomass Production. Trends Biotechnol. 2013, 31 (4), 233-239. https://doi.org/10.1016/j.tibtech.2012.12.005.

(27) Markou, G.; Chatzipavlidis, I.; Georgakakis, D. Carbohydrates Production and Bio-Flocculation Characteristics in Cultures of Arthrospira (Spirulina) Platensis: Improvements Through Phosphorus Limitation Process. Bioenergy Res. 2012, 5 (4), 915-925. https://doi.org/10.1007/s12155-012-9205-3.

(28) Depraetere, O.; Pierre, G.; Deschoenmaeker, F.; Badri, H.; Foubert, I.; Leys, N.; Markou, G.; Wattiez, R.; Michaud, P.; Muylaert, K. Harvesting Carbohydrate-Rich Arthrospira Platensis by Spontaneous Settling. Bioresour. Technol. 2015, 180, 16-21. https://doi.org/10.1016/j.biortech.2014.12.084.

(29) Toyoshima, M.; Aikawa, S.; Yamagishi, T.; Kondo, A.; Kawai, H. A Pilot-Scale Floating Closed Culture System for the Multicellular Cyanobacterium Arthrospira Platensis NIES-39. J. Appl. Phycol. 2015, 27 (6), 2191-2202. https://doi.org/10.1007/s10811-014-0484-2.

(30) Binnig, G.; Quate, C. F.; Gerber, C. Atomic Force Microscope. Phys. Rev. Lett. 1986, 56 (9), 930934.

(31) Besson, A.; Guiraud, P. High-PH-Induced Flocculation-Flotation of the Hypersaline Microalga Dunaliella Salina. Bioresour. Technol. 2013, 147, 464-470. https://doi.org/10.1016/j.biortech.2013.08.053. 
(32) Besson, A.; Formosa-Dague, C.; Guiraud, P. Flocculation-Flotation Harvesting Mechanism of Dunaliella Salina: From Nanoscale Interpretation to Industrial Optimization. Water Res. 2019. https://doi.org/10.1016/j.watres.2019.02.043.

(33) Passow, U.; Alldredge, A. L. Distribution, Size and Bacterial-Colonization of Transparent Exopolymer Particles (TEP) in the Ocean. Mar. Ecol. Prog. Ser. 1994, 113, 185-198. https://doi.org/10.3354/meps113185.

(34) Francius, G.; Tesson, B.; Dague, E.; Martin-Jézéquel, V.; Dufrêne, Y. F. Nanostructure and Nanomechanics of Live Phaeodactylum Tricornutum Morphotypes. Environ. Microbiol. 2008, 10 (5), 1344-1356. https://doi.org/10.1111/j.1462-2920.2007.01551.x.

(35) Zarrouk, C. Contribution à l'étude d'une cyanophycée: Influence de divers facteurs physiques et chimiques sur la croissance et la photosynthèse de Spiruline maxima (Setch et Gardner) Geitler. PhD Thesis, Univeristé de Paris: Paris, 1966.

(36) Miller, A. G.; Colman, B. Evidence for HCO3- Transport by the Blue-Green Alga (Cyanobacterium) Coccochloris Peniocystis1. Plant Physiol. 1980, 65 (2), 397-402.

(37) Filali Mouhim, R.; Cornet, J.-F.; Fontane, T.; Fournet, B.; Dubertret, G. Production, Isolation and Preliminary Characterization of the Exopolysaccharide of the Cyanobacterium Spirulina Platensis. Biotechnol. Lett. 1993, 15 (6), 567-572. https://doi.org/10.1007/BF00138541.

(38) Reddy, K. J.; Soper, B. W.; Tang, J.; Bradley, R. L. Phenotypic Variation in Exopolysaccharide Production in the Marine, Aerobic Nitrogen-Fixing Unicellular Cyanobacterium Cyanothece Sp. World J. Microbiol. Biotechnol. 1996, 12 (4), 311-318. https://doi.org/10.1007/BF00340206.

(39) Shiraishi, H. Association of Heterotrophic Bacteria with Aggregated Arthrospira Platensis Exopolysaccharides: Implications in the Induction of Axenic Cultures. Biosci. Biotechnol. Biochem. 2015, 79 (2), 331-341. https://doi.org/10.1080/09168451.2014.972333.

(40) Vandamme, D.; Foubert, I.; Fraeye, I.; Muylaert, K. Influence of Organic Matter Generated by Chlorella Vulgaris on Five Different Modes of Flocculation. Bioresour. Technol. 2012, 124, 508511. https://doi.org/10.1016/j.biortech.2012.08.121. 
(41) Beuckels, A.; Depraetere, O.; Vandamme, D.; Foubert, I.; Smolders, E.; Muylaert, K. Influence of Organic Matter on Flocculation of Chlorella Vulgaris by Calcium Phosphate Precipitation. Biomass Bioenergy 2013, 54, 107-114. https://doi.org/10.1016/j.biombioe.2013.03.027.

(42) Chopinet, L.; Formosa, C.; Rols, M. P.; Duval, R. E.; Dague, E. Imaging Living Cells Surface and Quantifying Its Properties at High Resolution Using AFM in QI ${ }^{\mathrm{TM}}$ Mode. Micron Oxf. Engl. 1993 2013, 48, 26-33. https://doi.org/10.1016/j.micron.2013.02.003.

(43) Hertz, H. Ueber Die Beruhrung Fester Elastischer Korper. J. Reine Angew. Math. 1881, 156-171.

(44) Formosa-Dague, C.; Feuillie, C.; Beaussart, A.; Derclaye, S.; Kucharíková, S.; Lasa, I.; Van Dijck, P.; Dufrêne, Y. F. Sticky Matrix: Adhesion Mechanism of the Staphylococcal Polysaccharide Intercellular Adhesin. ACS Nano 2016, $10 \quad$ (3), 3443-3452. https://doi.org/10.1021/acsnano.5b07515. 


\section{Figure Captions}

Figure 1. Schematic representation of the culturing protocol and conditions. A. platensis cells extracted from a maintaining tank where cell growth is low (outdoor lighting and temperature, in a $200 \mathrm{~L}$ tank) are cultured in a 6 L PBR in moderate growth conditions. This PBR is diluted every 5 days to an $\mathrm{OD}(680 \mathrm{~nm})$ of 0.3 , before stationary phase is reached. To perform the experiments, cells cultured in the inoculum PBR during 1, 4 or 7 weeks (culture 1, 2 and 3 respectively) are harvested by filtration: $2 \mathrm{~g}$ of the cells are then inoculated into the experiments PBR at high growth conditions in culture medium containing different concentrations of NaHCO3.

Figure 2. Optical imaging of EPS produced by A. platensis grown at different $\mathrm{NaHCO}_{3}$ concentrations. Optical image of $A$. platensis cells from culture 1, grown at a $\mathrm{NaHCO}_{3}$ concentration of (a) $0.025 \mathrm{~mol} / \mathrm{L}$, (c) $0.05 \mathrm{~mol} / \mathrm{L}$ and (e) $0.1 \mathrm{~mol} / \mathrm{L}$. The blue aggregates correspond to Alcian blue stained polysaccharides. Images in (b), (d) and (f) are the binary images of the blue signals from the images respectively in (a), (c) and (e). Scale-bar corresponds to $50 \mu \mathrm{m}$. (g) Histogram showing the average percentage of the area covered by EPS for A. platensis cells cultured at the different $\mathrm{NaHCO}_{3}$ concentrations. The stars indicate that the differences observed are significant at a $p$-value $<0.05$ (Mann-Whitney test).

Figure 3. Growth rate of $A$. platensis under different $\mathrm{NaHCO} 3$ concentrations. Biomass concentration as a function of time for (a) Culture 1 (1 week of culture in the inoculum PBR), (b) Culture 2 (4 weeks of culture in the inoculum PBR) and (c) Culture 3 (7 weeks of culture in the inoculum PBR) at a $\mathrm{NaHCO}_{3}$ concentration of $0.025 \mathrm{~mol} / \mathrm{L}$ (blue line), $0.05 \mathrm{~mol} / \mathrm{L}$ (red line) and $0.1 \mathrm{~mol} / \mathrm{L}$ (green line). (d) Histogram showing the growth factor $\mu(\mathrm{mg} / \mathrm{L} / \mathrm{h})$ of the 3 different cultures at the different $\mathrm{NaHCO}_{3}$ concentrations. 
Figure 4. Flocculation/flotation harvesting of $A$. platensis at different $\mathrm{NaHCO}_{3}$ concentrations. (a) Images extracted from a video recording of the flocculation/flotation of the cells from Culture 1 in a laboratory-scale DAF device. The left flotation-test beaker contains cells grown at a $\mathrm{NaHCO}_{3}$ concentration of $0.025 \mathrm{~mol} / \mathrm{L}$, the middle flotation-test beaker contains cells grown at a $\mathrm{NaHCO}_{3}$ concentration of $0.05 \mathrm{~mol} / \mathrm{L}$, and the right flotation-test beaker contains cells grown at a $\mathrm{NaHCO}_{3}$ concentration of $0.1 \mathrm{~mol} / \mathrm{L}$. Prior to white waters injection, the cells are left to flocculate during $20 \mathrm{~min}$ under agitation. (b) Photograph of filters used to filtrate the treated phase of the cells from Culture 1 after flocculation/flotation. The top filter corresponds to the treated phase of cells grown at a $\mathrm{NaHCO}_{3}$ concentration of $0.025 \mathrm{~mol} / \mathrm{L}$, the middle filter corresponds to the treated phase of cells grown at a $\mathrm{NaHCO}_{3}$ concentration of $0.05 \mathrm{~mol} / \mathrm{L}$, and the bottom filter corresponds to the treated phase of cells grown at a $\mathrm{NaHCO} 3$ concentration of $0.1 \mathrm{~mol} / \mathrm{L}$. (c) Histogram showing the flocculation/flotation efficiency of the cells from the 3 different cultures at the different $\mathrm{NaHCO}_{3}$ concentrations.

Figure 5. AFM multiparametric imaging of $\boldsymbol{A}$. platensis cells before harvesting. (a) AFM height image of an isolated aggregate of EPS and (b) cross-section taken along the grey line in (a). (c) Corresponding nanomechanical image of the isolated EPS aggregate presented in (a) and (d) histogram presenting the distribution of the Young modulus values obtained on 3 different isolated aggregates of EPS. (e) Corresponding adhesion image of the isolated EPS aggregate presented in (a) and (e) histogram presenting the distribution of the adhesion values obtained on 3 different isolated aggregates of EPS. Scale-bars correspond to $5 \mu \mathrm{m}$. 


\section{Graphical Abstract}

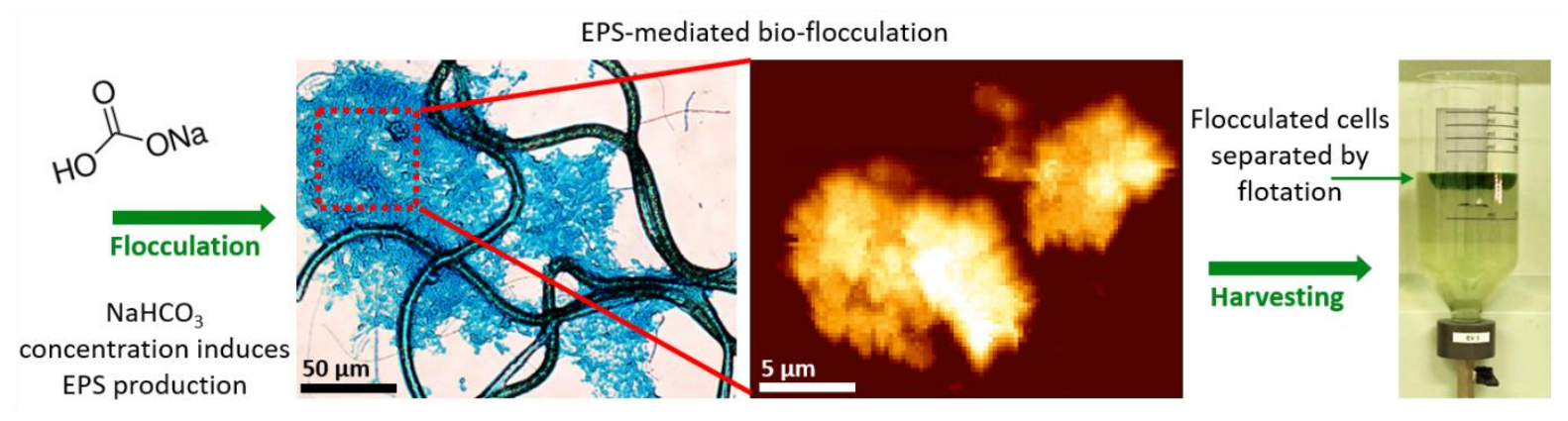

\section{Synopsis}

Providing culture conditions that allow both production of an EPS-rich microalgae biomass and efficient flocculation/flotation harvesting to make the production of microalgae-based biopolymers cost-effective 